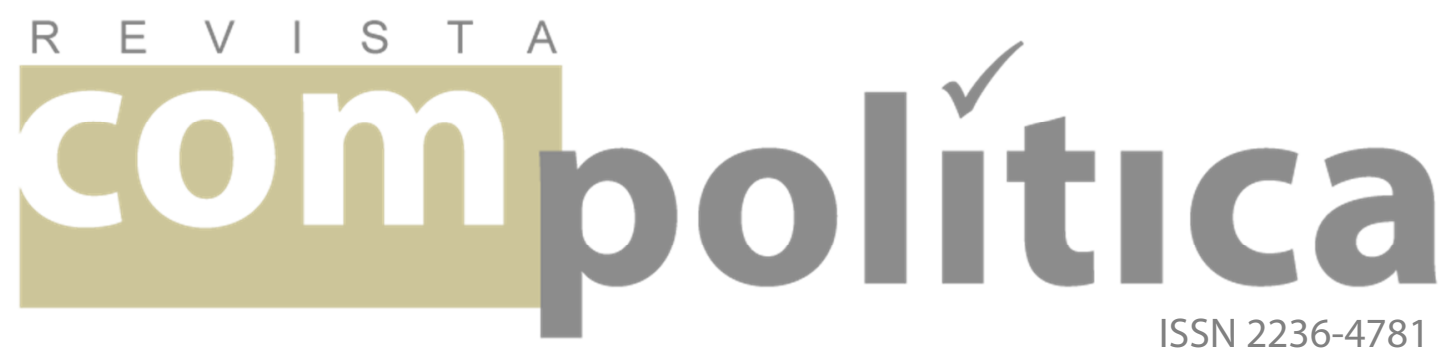

\title{
A articulação de jornalismo e espaços públicos na Ilustração Inglesa
}

\section{[The articulation of journalism and public spaces in the English Illustration]}

\section{RESUMO}

O Iluminismo, pensado a partir de sua vinculação com os espacos de sociabilidade, sua dependência do trânsito, circulação a apresentação contínua da novidade, caracteriza uma série de transformacões no ambiente urbano. Habermas notou essa importância ao sugerir o papel dos cafés e salões para a formação de um círculo de retroalimentação entre os jornais e as conversações: estas alimentavam a pauta periódica dos jornalistas, tanto quanto os jornais reforçavam determinados círculos de sociabilidade urbanos. O papel desses espaços no que diz respeito a abrigar uma cultura da interação, contudo, foi atravessado por dispositivos não previstos pela teoria habermasiana, inclusive no que diz respeito à forte tendência à formaç̃o de clubes com interesses bem específicos, em cujo bojo estavam presentes várias interdições sociais. Nosso interesse, no âmbito deste artigo, é sugerir, a partir dos caminhos traçados por Habermas, vias que tornem possivel perceber, de forma mais alargada, os vínculos do jornalismo com a esfera pública, pensado como forma de apresentação regular da novidade e embutido nas práticas da cidade moderna.

Palavras-chave: Iluminismo, Jornalismo, Tavernas, Cafés, Esfera pública.

Revista Compolítica 5 (1), 2015

Recebido em 4 de abril de 2014

Aprovado em 5 de abril de 2014

\section{MUNARO, Luís Francisco}

Professor do Departamento de Comunicação Social da UFRR, doutor em História pela UFF

[Professor at the Social Communication Department at Roraima Federal University, PhD in History from Fluminense Federal University]

<luismunaro@yahoo.com.br>

\section{ABSTRACT}

The Enlightenment, thought from its connection with sociability places, dependence of transit, circulation and continued presentation of news, features a series of transformations in the urban environment. Habermas noted that importance by suggesting the role of coffeehouses and taverns for the formation of a feedback circle between the newspapers and the public discussions: these ones fed a regular agenda of journalists as much as newspapers reinforced some urban sociability circles. The role of these spaces with regard to build a culture of interaction, however, was crossed by aspects unforeseen by Habermas theory, including with regard to the strong tendency to form clubs with very specific interests, in which a lot of social prohibitions were present. Our interest in the context of this article is to suggest, from the paths traced by Habermas, ways that make it possible to realize, more broadly, journalism links with the public sphere, thought as a form of regular presentation of new and attached in practices of the modern city.

Keywords: Enlightenment, Journalism, Taverns, Coffechouse, Public Sphere.

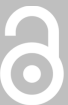

Open Access Journal 


\title{
A articulação de jornalismo e espaços públicos na llustração Inglesa
}

MUNARO, Luís Francisco

\begin{abstract}
A s práticas e representações modernas não nasceram de forma 1 súbita dos escombros do Antigo Regime e nem concernem à realização de um futuro escatológico no qual a Razão aparece como a tutora dos mais altos valores humanos e sua possibilidade suprema de realização. Ao contrário dessa visão teleológica que baliza o moderno entre dois pontos fixos, a modernidade se realiza permanecendo vinculada a um discurso tradicional em que o passado resiste no bojo da política crescente de racionalização e instrumentalização dos espaços levada a cabo pelos homens do Iluminismo.
\end{abstract}

Estudar a consolidação das práticas modernas é um esforço que diz respeito à investigação dos espaços urbanos específicos que materializaram o ânimo intelectual presente no discurso das Luzes. Existem bons ganhos de compreensão quando optamos por vincular - Iluminismo à materialidade dos espaços de socialização que demarcam novas formas de subjetivação e circulação de seres humanos. Noutras palavras, especular as possibilidades de diálogo e trânsito de atores considerados porta-vozes das Luzes a partir dos espaços que frequentaram é avançar no que diz respeito ao esforço de compreender a modernidade e o papel que nela coube ao jornalismo.

A cidade constitui um importante documento para a compreensão das formas de viver e atua como um condicionante dessas mesmas expressões de vida. A secularização da cidade faz parte das práticas 
modernas e implica uma diferença importante na forma de se relacionar com os outros e experimentar o mundo. Em seu estudo $A$ Galáxia de Gutenberg (1972), Marshall McLuhan observava que novos condicionamentos psíquicos surgiam com a iminência de novas práticas sociais, como aquela que dizia respeito à impressão e disseminação de material escrito. Jonathan Crary, de forma complementar, sugeria que o confronto do indivíduo com a cidade em pleno processo de modernização incluía transformações bastante significativas nas formas de enxergar o mundo. Ou seja, o mundo é tornado um "objeto" diante do qual o observador se isenta de relações subjetivas, o que, segundo a crença iluminista, poderia danificar a compreensão do "mundo em si mesmo" (CRARY,1992, pp. 10-11).

Essa discussão ajuda a dar uma dimensão das transformações nos espectros de ações dos indivíduos, limitados como eram pelas circunstâncias dos ambientes urbanos. É evidente que a transformação destes ambientes está ligada à emergência de novas formas de discurso e cultura política, aspectos nucleares da história moderna. Não obstante, os meios que disponibilizavam o trânsito desses discursos e seu espraiamento são igualmente fundamentais para a compreensão do relacionamento dos homens com as letras, lembrando que Addison e Steele, sem cafés ou sem tavernas, dificilmente teriam construído o jornal The Spectator, e nem, tampouco, Daniel Defoe teria dado à luz Robinson Crusoe.

Nesse sentido, o Iluminismo foi alimentado por um intercâmbio mais sofisticado entre os indivíduos, a ponto de, muito pertinentemente, Lawrence Klein chamá-lo de "Iluminismo como conversação" (KLEIN, 2001, p. 148). Além disso, os espaços crescentemente disponíveis favoreceram a circulação de material impresso que, tanto quanto a própria cidade, faziam parte de uma nova forma de 
compreender a realidade. É importante lembrar que legislações específicas, na Inglaterra, garantiam uma margem de ação mais alargada, sobretudo no que concerne à expressão escrita e à circulação em espaços de discussão politizada, ainda que seja um erro considerá-los idealmente democráticos. A cultura do iluminismo é uma cultura de circulação de ideias em que não expor a própria ideia, a luz recebida, representa ausência com relação à "razão prática". Como sugere Carla Hesse, "a impressão e publicação foram não só os mecanismos culturais mais importantes para a disseminação de ideias iluministas; elas eram a personificação do Iluminismo em ação - o meio era a mensagem - espalhando luz" (HESSE, 2004, p. 368 - tradução nossa).

Observando a materialidade que encarna os discursos modernos, pretendemos lançar questões sobre a vivência urbana e suas possibilidades e limitações dentro das práticas ilustradas. Isto diz respeito a refletir o pano de fundo que a cidade forneceu para a grande opulência e o desenvolvimento de material escrito, subsidiando um surto de publicações profissionais no seio das quais o jornalismo figurou como um fenômeno de suma importância. Não mais do que cem anos depois da criação de Addison e Steele, já circulavam pelo menos dois grandes diários independentes em Londres, The Morning Chronicle e The Times e duas revistas fundamentais para a identificação dos partidos Tory (que reunia, basicamente, elementos de filiação conservadora e ascendência aristocrática) e Whig (partido liberal vinculado, sobretudo, aos movimentos protestantes), chamadas Quarterly Review e Edinburgh Review.

Os literatos ingleses documentaram a crescente transformação do ofício do escritor, a perda dos valores mais abstratos em detrimento de uma escrita rápida e acessível ao maior número, o que é, 
indiscutivelmente, característica do jornalismo enquanto prática organizadora de novas formas de urbanidade. Alexander Pope e Jonathan Swift, por exemplo, mencionavam as mutações literárias que passava Londres junto com seus espaços. Segundo The Dunciad (1728), de Pope, os literatos ingleses eram confrontados diariamente com um universo mental insalubre para a atividade intelectual. Seus esforços voltados para a construção de uma elite letrada estariam sendo deixados de lado em favor da rapidez cotidiana apresentada pelos vários nichos jornalísticos e pelas subculturas literárias (POPE apud ROGERS, 1972, p. 13).

As ideias modernas, que aqui pretendemos apresentar em sua vinculação com os espaços, em sua dependência de trânsito, circulação e apresentação contínua da novidade, ajudam a caracterizar uma transformação contínua na organização da cidade (GOODMAN, 2001, p. 130). Habermas notou essa importância ao sugerir o papel dos cafés e dos salões para a formação de um círculo de retroalimentação entre os escritos e as conversas: estas ajudavam a manter a pauta periódica dos jornalistas tanto quanto os próprios jornais reforçavam os círculos de conversação (HABERMAS, 2003, p. 59). As representações iconográficas de época demonstram isso com alguma clareza: "The Silent Meeting" (1794) de Isaac Cruickshank, por exemplo, sugere a presença do jornal in octavo nas mãos dos conversadores na taverna e no café; "The Coffeehouse patriots" (1781), de W. Dickinson e "A peep into the city of London Tavern" (1817), de um "amador inglês", demonstram a presença frequente de panfletos no interior de discussões políticas.

A partir destes dados, o interesse deste artigo é entrecruzar elementos da esfera pública, sobretudo relativos ao jornal, ao panfleto, à taverna e ao café para compreender a catalisação de práticas jornalísticas num ambiente politicamente renovado. A 
atenção, portanto, não recai sobre as dificuldades de configurar a esfera pública e a desatenção de Habermas com relação às suas restrições historiográficas. Também descarta as várias intervenções que o próprio Habermas faria, posteriormente, no conceito de esfera pública (SILVA, 2001). O objetivo é, sobretudo, lançar indagações sobre como essas transformações de espaço abrigaram uma nova forma de cultura escrita, ligada à apresentação regular da novidade e intimamente dependente do esforço interativo e popularizador do conhecimento, o jornalismo.

\section{A imprensa na Inglaterra}

Estudar o fenômeno que transformou a vida social europeia - e não só da Europa - a partir apenas do círculo de intelectuais vinculados ao exercício formal da filosofia ou da vida política diminui a possibilidade de compreender a variedade de práticas e representações envolvidas na cultura das Luzes, inclusive aquelas não destinadas à impressão livresca. Alguns esforços de desconstrução do pensamento do século XVIII comprovam os ganhos de não se investir apenas nos escritos consagrados pelo público. Para tanto, por exemplo, é possível mencionar como Robert Darnton descobriu nas canções populares, notícias manuscritas e impressos clandestinos um rico material de estudos para se entender as transformações da vida e divulgação de informações na cidade de Paris (DARNTON, 2005). Ou, de outra forma, como Pierre Rosanvallon ajudou a compreender a produção literária não como um arcabouço fechado de ideias consolidadas no escritório dos literatos, mas sim como o fermento para a construção de mudanças identificadas com a modernidade (ROSANVALLON, 2002). Em outras palavras, o fenômeno iluminismo não pode ser compreendido através da via 
única do material livreiro. Isso implica considerar, por exemplo, a limitação da asserção de Ernst Cassirer ao afirmar que "o Iluminismo, que ainda é geralmente tratado como uma mistura eclética de elementos dos mais diversos pensamentos, é de fato dominado por algumas grandes ideias fundamentais expressas através de rigorosa consistência e em arranjo exato" (CASSIRER apud WRIGHT, 2001, p. 88 - tradução nossa). A sugestão de Ernst Cassirer parte do ponto de vista de que a experiência letrada concentrada em torno da produção dos filósofos poderia caracterizar de forma completa a experiência social iluminista. Trata-se de um preconceito construído pelo próprio pensamento da época, como aquele dos literatos Jonathan Swift e Alexander Pope, para quem os escritores não premiados estariam longe de caracterizar qualquer experiência literária efetiva ou contribuição urbana significativa.

Como corrige Roy Porter, a tendência em limitar a caracterização do Iluminismo a grupos de indivíduos exclusivamente identificados com o ofício de pensar acabou afastando a investigação de outras experiências vinculadas ao mesmo fenômeno, inclusive aquelas jornalísticas. Segundo o autor, essa visão estereotipada do Iluminismo teria concentrado a concepção histórica e filosófica do movimento em torno de uma propaganda quase uniforme do pensamento francês (PORTER, 1994, p. 253). Roy Porter sugere que, por outro lado, a Constituição Inglesa tornou os projetos de liberdade que se tornariam uma reivindicação dos philosophes franceses um símbolo da própria nação britânica. Isso implicava, na teoria, a garantia da liberdade individual e, portanto, a liberdade de reunião e trânsito de ideias, o que tornou várias das reivindicações francesas menos necessárias na Grã-Bretanha. Além disso, permitiu a estruturação de ambientes favoráveis ao trânsito de ideias e reuniões intelectuais, identificados por Habermas com os vários processos 
informais de formação de opinião caracterizados, genericamente, como esfera pública.

É importante lembrar que a expressão de Habermas tem sofrido críticas bastante contundentes. Segundo a noção de esfera pública, em sua forma tradicional, ela:

\begin{abstract}
pode ser concebida, antes de mais, como a esfera em que pessoas privadas se juntam enquanto um público; bem cedo, reclamaram que essa esfera pública fosse regulada como se estivesse acima das próprias autoridades públicas; de forma a incluí-las num debate sobre as regras gerais que governam as relações da esfera da troca de bens e de trabalho social basicamente privatizada, mas publicamente relevante (HABERMAS, apud SILVA, 2001, p. 118).
\end{abstract}

A polarização binária entre público e privado não ajuda a perceber como o próprio Antigo Regime estruturou sua representatividade política através da esfera pública. Ela não era, portanto, um espaço que carecia por completo da influência de setores da nobreza, apesar de a rejeição aos nobres ser um tanto quanto explícita. Da mesma forma, não se apresentava como um ambiente perfeitamente democrático, a julgar pelas várias interdições relativas à participação de mulheres. Por fim, trata-se mais de um tipo-ideal histórico, passível de ser tomado como ponto de partida para estudos da história do jornalismo.

A organização da esfera pública na Inglaterra foi acompanhada pelo amadurecimento de uma produção periódica regular destinada às pessoas privadas, no caso particularmente expressivo do jornal The Spectator (1711), primeiro jornal propriamente doméstico, e do The Morning Chronicle (1769), a quem coube o pioneirismo de investir numa rede de repórteres independente do poder público (WASSON, 2006, p. 76). Ao contrário das Gazetas, tipicamente produzidas sob a orientação do Antigo Regime, ainda muito presentes na França do século XVIII, estes jornais começaram a ser direcionados para um 
público mais aproximado da vivência privada e da vida comercial (MELTON, 2001, p. 7). Evidentemente, por outro lado, a garantia constitucional à liberdade de imprensa tornou um imperativo da vida política a sua inserção no debate impresso, como o comprovam a construção dos grandes semanários de orientação Tory e Whig (COOPER-RICHET, 2006).

No que concerne à construção dessa rede de impressos, o literato Alexander Pope dá testemunhos importantes. Segundo sua percepção elitizada da cultura letrada, o surgimento da imprensa regular apressava a deterioração da palavra escrita. 0 fato de ele verbalizar precocemente essa denúncia comprova a importância de formas alternativas de literatura na organização da vida diária em Londres:

\begin{abstract}
Pope, sem dúvida porque viveu no início de uma nova era de publicação popular e jornalismo semanal, tomou uma posição firme contra a subcultura que ele viu invadindo o território vedado da literatura. No poema Dunciad, de 1729, ele atacava as subculturas escritas: o erudito pedante como Hearne ou Theobald; o jornalista semanal como Roome e Concanen; o escritor hack como Oldmixon; o escritor popular, como Mrs Centlivre, Mrs Haywood, Ned Ward, ou o autor de Robinson Crusoe; o editor sem vergonha como Edmund Curll (WATT apud ROGERS, p. 188 - tradução nossa).
\end{abstract}

Nos escritos de Alexander Pope, Grub Street se tornou um topônimo para a crescente ou deteriorada atividade literária da cidade de Londres que, ao mesmo tempo, foi responsável pela expansão dos círculos escritos para além dos gabinetes dos filósofos. Por outro lado, considerar a importância histórica dos escritos que se dispersavam através da Grub Street permite ampliar o entendimento da esfera pública como sugerida por Habermas, na medida em que ela abarcava escritores incapazes de se inserir no debate impresso racionalizado sobre formas possíveis de governo. Nem por isso, contudo, se tornaram menos influentes, da mesma forma que os 
mexericos descritos por Robert Darnton na "Árvore de Cracóvia" em Paris (2005).

Num primeiro momento, com Addison e Steele, o jornal procurou demarcar sua independência da esfera política, sugerindo um ambiente doméstico independente. A formação da imprensa britânica no início do século XVIII é marcada justamente pela tentativa de isenção dos jornais dos debates políticos - de forma ainda mais nítida isso foi percebido na França, através dos jornais literários -, ao contrário do que acontecerá na metade do século, com o surgimento dos jornais vinculados aos grupos Tory e Whig. A famosa empreitada de Addison e Steele aponta para um ambiente doméstico que anseia ser independente da interferência política direta. De forma semelhante, os "semanários morais" contestavam, segundo Melton, o predomínio cultural da corte sobre os círculos de conversação:

\begin{abstract}
Abstendo-se de tocar em questões políticas, o semanário moral implicitamente distinguiu o social do político, o privado do público e, assim, apontou para noções modernas da sociedade civil como uma esfera autônoma do Estado. No contexto do século XVIII, a validação social dos semanários morais como uma arena autônoma e não-política implicitamente contestou o domínio cultural da Corte. Não é por acaso que, na Inglaterra, a popularidade dos semanários morais veio num momento em que a influência cultural da corte real diminuía rapidamente (MELTON, 2001, p. 97 - tradução nossa).
\end{abstract}

O envolvimento da imprensa com a vida política se tornará mais comum a partir de 1750 (HABERMAS, 2003). O lançamento do jornal Morning Post em 1772 exemplifica de forma clara como os jornalistas e editores jogavam com políticos e a importância de os ministros terem gazetas favoráveis às suas ações. Morning Post e The Morning Chronicle podem ser considerados o pontapé para o desenvolvimento do jornalismo enquanto uma prática profissional enraizada na urbanidade, isto é, como uma forma de escrita regular concernente à 
organização do espaço público - quando, antes, Addison e Steele estavam mais preocupados com a organização do ambiente doméstico e sua distinção do público.

Ainda Alexander Pope observava de forma negativa o surgimento de uma esfera de jornalistas que monopolizavam de forma crescente a atividade escrita. Para ele, começava a predominar um tipo de escritor:

regular, 'hack paid' que depende inteiramente da escrita itinerante para o próprio sustento. Pope não valoriza este homem porque sua participação na literatura é comercial. Se o 'hack' não entregar a mercadoria, ele não vai comer; por isso, ele é obrigado a aceitar qualquer comissão, mesmo que indigna, e não pode realizar uma busca de agrupamento de tópicos, temas e estilos que a teoria do Renascimento exigiu como prelúdio válido da escrita criativa (ROGERS, 1972, p. 189 - tradução nossa).

Pope enuncia o surgimento de uma vida literária capaz de extravasar os gabinetes dos filósofos. Ainda que não reconheça seu papel importante na popularização da literatura e expansão do círculo de sociabilidades civis, ele pontua com clareza o grau de dispersão dessas novas plataformas escritas. Tanto elas podem ser irregulares e agressivas, como no caso dos escritos de Grub Street, como comercialmente sólidas, como no caso dos jornais que começam a circular com periodicidade cada vez mais bem definida.

A produção periódica voltada para temáticas políticas acompanha a formação de partidos e cumpre um papel importante no delineamento do Estado Nacional Inglês. Para exemplificar o papel da imprensa nesse processo, vale lembrar que foi a articulação precoce dos setores monárquicos com alas mais progressistas da sociedade que garantiu a permanência do rei enquanto uma figura com papel simbólico importante na Inglaterra (HABERMAS, 2003), ao contrário do que aconteceu na França quando o rei, buscando 
estender o círculo de representação da Corte através das gazetas tradicionais, se tornou uma figura com pouca influência civil.

$\mathrm{Na}$ Inglaterra, o fato de o rei ser um símbolo nacional fez com que se tornasse um alvo privilegiado dos jornalistas. Tanto quanto era capaz de criar uma imagem vigorosa do monarca, a imprensa era capaz de desmontá-lo. Cannadine exemplifica, por exemplo, os episódios envolvendo o rei George III:

Embora as grandes cerimônias reais fossem
completamente cobertas tanto pelos jornais
interioranos quanto pelos da metrópole, a imprensa
como um todo continuava hostil à monarquia. Nas
primeiras décadas do século XIX, as críticas feitas na
imprensa londrina por Gillray, Rowlandson e os
Cruikshanks transformaram a monarquia sem dúvida
no tema e no alvo mais comum dos caricaturistas
(CANNADINE, 1997, pp. 120-121).

Cumpre ressaltar, uma vez tendo criado relativa noção do papel da imprensa na configuração de um espaço público na Inglaterra, a forma como o próprio discurso da imprensa se desenrolava em determinados espaços de circulação, como é o caso das tavernas da Grub Street e da Cornhill Street, ou dos cafés mencionados por Habermas como princípio da esfera pública (2003), levantados de forma precisa por Brian Cowan e concentrados, sobretudo, em Broad Street (2005). A existência desses espaços é fundamental para o surgimento de uma consciência pública ligada à discussão dos problemas nacionais. Os espaços estão entranhados na cidade tanto quanto está o jornalismo como literatura regular primeiramente derivada, segundo Habermas, dos correios ordinários (2003).

Os critérios dessa nova forma de literatura estavam intimamente vinculados à troca epistolar permanente de informações. A transformação da notícia em mercadoria vai ligá-la aos critérios de novidade da economia capitalista. A velocidade dos escritos se acelera gerando, no caso inglês, substrato material para aquela 
crítica típica de Pope e Swift com relação ao conteúdo dispersivo dos jornais (MELTON, 2001). Sua importância, contudo, como elemento de popularização da palavra escrita e da vivência civil, bem como seu papel estruturador de sociabilidades modernas, já está inequivocamente lançado.

\section{Espaços de intercâmbio de ideias e o jornalismo}

Os espaços de socialização civil se multiplicavam em Londres à medida que aumentava a necessidade de transitar informações e se adensavam as relações comerciais entre os indivíduos. Os mesmos papeis escritos que, na linguagem de Habermas, caracterizavam a troca epistolar privada e forneceram, aos poucos, fundamentos para uma troca regular de informações na esfera pública, circulavam por estes novos ambientes de forma mais anônima e forneciam temas e argumentos para a estruturação das sociabilidades de grupos ascendentes de indivíduos vinculados à vida comercial (HABERMAS, 2003). Já no século XVII, era possível perceber o grau de intimidade entre as tavernas e o fluxo de notícias proveniente da circulação de estrangeiros. No poema "News from the coffeehouse" (1667) de Edmund Crouch, por exemplo, lê-se que:

\footnotetext{
You that delight in Wit and Mirth, And long to hear such News, As comes from all Parts of the Earth, Dutch, Danes, and Turks, and Jews. I'll send yee to a Rendezvous, Where it is smoking news; Go hear it at a Coffee-house; It cannot but be true (no original).
}

Os estrangeiros que chegaram em Londres nos séculos XVII e XVIII eram tocados pelo clima cosmopolita da cidade, explícito em grande quantidade de albergues limpos, hotéis e ruas iluminadas que abrigavam uma promissora vida noturna. Longe de um dado 
contingente, a vida noturna efetivamente permitia a extensão das sociabilidades, tornando-se assim um ingrediente à parte na dinâmica da vida londrina. Todo o processo de reconstrução por que passa a cidade é observado pelo visitante austríaco Johann Archenholz que, em meados do século XVIII, elaborou a seguinte descrição:

\begin{abstract}
O contraste com as partes ocidentais da metrópole é surpreendente; as casas lá são quase novas e de uma excelente construção; as praças são magníficas, as ruas são construídas em linhas retas e perfeitamente bem iluminadas: nenhuma cidade na Europa é melhor pavimentada. Se Londres inteira fosse igualmente bem construída, não haveria no mundo inteiro lugar comparável (ARCHENHOLZ apud PORTER, 1990, p. 39 tradução nossa).
\end{abstract}

A estrutura da cidade é modificada à medida que as relações sociais adquirem um estágio mais complexo, tanto quanto surgem ideias relativas à reconstrução do espaço urbano de forma a deslocar as sociabilidades, antes guardadas nos salões aristocráticos, para espaços destinados ao público anônimo. O discurso iluminista se entrecruza, assim, com uma práxis de transformação do mundo. A cidade adquire a coloração dessas novas ideias e, na medida em que se tinge delas, ajuda a fazer transitar os discursos ilustrados. Esses discursos não são explicitamente filosóficos: apenas por dizerem respeito à circulação e popularização do conhecimento, já ilustram o esforço pedagógico das Luzes.

Os estrangeiros chegados na cidade poderiam encontrar facilmente formas de sociabilidade independentes dos círculos de conversação provincianos da corte (ELIAS, 2001). A vida moderna é a vida de uma cidade que se abre abandonando, em certo grau, a avaliação dos indivíduos pelas etiquetas apresentadas em espaços hierarquicamente organizados. Isso quer dizer, de um certo modo, privilegiar o cosmopolitismo no qual está implícita a possibilidade de 
receber a novidade, ainda que isso seja motivado, num primeiro momento, pelas necessidades comerciais.

Essa tolerância com o novo, característica dos principais espaços abertos ao público em Londres, as tavernas e cafés, facilitaria por si só a construção de sociabilidades jornalísticas mais sólidas. Esse testemunho é dado, ainda que de forma tardia, pelos próprios portugueses que noticiaram o crescimento da comunidade de emigrados políticos a partir de 1807. Na ocasião, o ciclo contínuo de migrações motivado pelas guerras na Península Ibérica permitiu a construção de um clube de negociantes na taverna City of London, localizada na rua Bishopsgate. Nesse clube, os portugueses estabeleceram sua defesa contra os círculos aristocráticos e o sistema de monopólios em Portugal clamando por reformas no sistema monárquico. Essas sociabilidades foram fundamentais para a articulação de uma cultura de periódicos portugueses em Londres (BOISVERT, 1973). Os jornalistas portugueses deixaram relatos importantes sobre a organização das comunidades emigradas e tornaram explícita essa abertura da cidade para as diferenças políticas e sociais. Quer dizer, não era difícil encontrar espaços onde se podia ir e conversar em outras línguas. Ou, em outras palavras, não era difícil encontrar espaços onde as notícias podiam ser intercambiadas abertamente, sendo assim incorporadas por estruturas jornalísticas (MUNARO, 2014).

Fundada em 1765, a taverna City of London possuía várias salas destinadas a reuniões com propósitos específicos. Seu papel na condição de construtora de identidades de grupo entre os próprios ingleses foi importante. Isso pode ser visto em vários documentos de época, entre os quais uma imagem datada de 1817, elaborada por um "amador irlandês", chamada "a peep into the City of London Tavern". Ela retrata a taverna como um ambiente onde se debate de 
forma entusiasmada ideias políticas e econômicas. Nela se percebe um indivíduo sobre uma mesa discursando para outros quinze indivíduos, entre os quais estão uma mulher e um negro. 0 balão principal diz que: "there is not a single industrial who can even partially comprehend my plan - I am not of your politics - I am not of your religion, not of any religion in the world - I move for a committee to consider the subject". Segundo a descrição, o indivíduo é o reformador Robert Owen, que segura em sua mão o panfleto "A new view of society".

A despeito do conteúdo político da cena, que envolve algumas figuras proeminentes da sociedade inglesa, importa aqui notar a disposição dos indivíduos em torno do debate de temas fundamentais para a vida civil. o condutor do meeting, chamado chairman, é aquele encarregado de manter a civilidade durante a discussão, fazendo prevalecer o debate de ideias. Ao redor do indivíduo que apresenta as suas ideias, os outros dialogam, carregando panfletos que também lhes fornecem inspiração política. Já parece claro, portanto, que a taverna é um ambiente de nítida motivação intelectual, capaz de abrigar a discussão aberta de projetos políticos e econômicos e de favorecer a circulação de jornais e, consequentemente, a popularização de ideias políticas.

James van Horn Melton constata, por outro lado, a pequena importância dos salões na sociedade de Londres e o grande fluxo de indivíduos existente nos cafés e tavernas. Se os salões foram uma referência na organização das sociabilidades da ilustração francesa, na Inglaterra, talvez pela maior independência da sociedade civil, os antigos saraus das madames foram relegados a um segundo plano. Especificamente no que diz respeito à figura feminina, Melton define como mais importantes os spas, através dos quais muitas mulheres 
chegaram a se tornar praticantes regulares de literatura (MELTON, 2001).

Ainda quanto às tavernas: se, no século XVIII, elas possuíam um apelo mais popular e mesmo plebeu, as várias leis contra bebedeira pública e a fiscalização policial tornaram-nas um lugar mais propício para o diálogo calmo e para a leitura de jornais. A disseminação da cultura do café e, posteriormente, do chá e do chocolate, contribuiu para reforçar estes costumes. Evidentemente, ao contrário do álcool, o café facilitava a extensão dos diálogos racionalizados e seu entrecruzamento com a cultura letrada. No início do século XVIII, a "casa de café", como lembra Cowan, dizia respeito a

\begin{abstract}
um lugar onde as pessoas se reuniam para beber café, ouvir as notícias do dia e, talvez, confraternizar com outros moradores da região e discutir assuntos de interesse mútuo. No entanto, para além desta identificação mais visível, o café guardava uma variedade de nuances. Apesar de instituição inovadora surgida em meados do século XVII, ele foi construído a partir de tradições familiares. O café era uma casa pública bem como as cervejarias, pousadas e bares que há muito tempo faziam parte da paisagem urbana britânica. O termo 'casa pública' capta bem a justaposição paradoxal do privado e as esferas públicas encontradas nesses locais, e o termo foi sendo cada vez mais utilizado para se referir ao lar aberto aos clientes para descanso e lazer [...] (COWAN, 2005, p. 79 tradução nossa).
\end{abstract}

Pode-se afirmar que há uma íntima relação entre esses espaços de animação intelectual e as bebidas neles consumidas, como se depreende do verdadeiro protagonismo de café e do chá na Ilustração inglesa. Contudo, como lembra Cowan, a relação não é imediata: o consumo do café é mais devido aos costumes dos virtuosi, inclinados a experimentar novidades culturais, do que à motivação intelectual intrínseca ao uso da cafeína. Além disso, é preciso lembrar que, logo na década de 1720, o café começou a perder espaço para o chá como principal bebida cafeinada inglesa, o que foi 
motivado pelo barateamento da produção de chá britânica e a competição das produções de café de Holanda e França (COWAN, 2005).

As tavernas e os cafés tornaram-se, assim, ambientes de nítida motivação intelectual. Os proprietários dispunham não apenas de mesas para o acomodamento de vários visitantes como também livros e periódicos contendo novidades. Quer dizer, um café era um local no qual, ainda que teoricamente, qualquer um podia ir para adquirir notícias. Melton procura detalhar essa relação:

\begin{abstract}
Por volta de 1729, a ligação entre os cafés e o jornalismo se tornou tão evidente que os proprietários do café de Londres solicitaram ao Parlamento um monopólio sobre a publicação de jornais. O Parlamento rejeitou seu plano para substituir os jornais existentes com uma 'Coffeehouse Gazette', mas o incidente ilustrou quão estreitamente os mundos do jornalismo e do café estavam entrelaçados (MELTON, 2001, p. 245 tradução nossa).
\end{abstract}

A afinidade entre a leitura de jornais e os cafés ultrapassava a mera disponibilidade de jornais, já que os jornalistas se alimentavam ativamente dos diálogos nutridos nestes espaços. Por outro lado, a conversação ativava o conteúdo jornalístico na memória do leitor, ajudando a hierarquizar os temas a partir do impulso que forneciam para a interação. Este promissor ambiente intelectual é bastante importante para a frutificação do jornalismo em sua forma moderna, ocasião em que assume, para usar a fórmula de Habermas, o papel de “esfera pública literária” (2003, p. 141). Para ilustrar a forma como essa interação acontecia, Habermas menciona The Spectator e suas formas de intercâmbio com públicos leitores, intimamente dependente do espaço do café: público dos cafés em objeto de suas discussões, mas também entendidos como parte integrante deles; isto se mostra no dilúvio de cartas, das quais os editores semanalmente publicavam uma seleção. As cartas dos 
leitores, quando o Spectator se separa do Guardian recebem uma instituição própria: na parte Oeste do café Button's é colocada uma cabeça de leão, por cuja garganta o leitor podia jogar as cartas. Também a forma de diálogo, que muitos artigos mantém, testemunha a proximidade da palavra falada. Transporta para um outro meio de comunicação, continua-se a mesma discussão para, mediante a leitura, reingressar no meio anterior, que era a comunicação (HABERMAS, 2003, p. 59).

O próprio Addison, é preciso lembrar, era um frequentador de cafés e utilizava os seus espaços para interagir e trocar notícias (COWAN, 2005). Como sugere Habermas, os artigos jornalísticos não apenas eram objeto ativo de conversas como se incorporaram, de forma definitiva, à paisagem dos cafés. O público participava - como através da boca de leão no café Button's - sobretudo através de cartas. Essa interação se tornou bastante promissora em virtude da própria Constituição britânica - lembrando que, em Paris, essa interação acontecia sobretudo através da via oral e informal, como no caso dos cardápios de notícias nos salões das madames ou das fofocas na "Árvore de Cracóvia” (DARNTON, 2005).

Além disso, os espaços britânicos favoreceram a construção de identidades de grupo e formação de nichos políticos, num fenômeno que Jason Kelly identificou como "mundo clubável” (2006, p. 762, "clubbable world" no original). Como detalha Melton:

\footnotetext{
As tavernas inglesas foram um lugar onde diversos públicos se cruzaram e, por vezes, interagiram. Originária como uma esfera predominantemente plebeia de sociabilidade, elas eram uma parte central do sistema de partidos emergentes, a expansão do reino da política popular e a vida associativa crescente da Inglaterra hanoveriana. Como um ponto de encontro para as elites políticas e grupos locais, bem como uma matriz organizacional para os clubes, sociedades e política extraparlamentares, elas atraíram um relativamente amplo espectro da sociedade inglesa (MELTON, 2001, p. 235 - tradução nossa).
}

Dessa forma, as tavernas poderiam se tornar um espaço de subjetivação incorporado à identidade dos frequentadores. Exemplo 
bastante claro disso diz respeito aos próprios portugueses, em cujas comunidades, em Londres, os clubes e os jornais possuíam estreita relação. Os jornais não apenas ajudavam a fornecer coesão interna para estes clubes como, também, coerência diante de outros grupos políticos. Eles ilustram a postura pública do clube e seu comprometimento com uma determinada fórmula liberal, identificando as notícias através dessa mesma postura.

Evidencia-se, a partir desses dados, a grande mobilidade social tornada possível através do número crescente de espaços de acesso público ou, então, espaços capazes de deixar em segundo plano as etiquetas na hora do aceite de integrantes, fenômeno no qual o jornal, enquanto escrita popularizada - mas ainda não popular cumpre importante papel. As novas formas de discurso que fazem propaganda das Luzes produzem efeitos nos usos do espaço urbano, que ora passa a tornar possível a circulação de indivíduos com fluidez semelhante à da palavra escrita. Tanto quanto a correspondência epistolar privada transforma-se em correios direcionados para públicos cada vez mais amplos, os espaços domésticos fechados que alimentavam a funcionalidade da etiqueta aristocrática deixam de ter um papel ativo na sociedade liberal organizada na cidade.

\section{Conclusão}

A cidade materializa as práticas e representações da cultura iluminista. Ela diz respeito a uma abertura ao novo em que a identidade é transformada continuamente por hábitos secularizados. É possível perceber como esse olhar inclui as formas de vivência e subjetivação de espaços específicos, que só poderiam existir a partir de uma práxis iluminista vinculada à busca pela liberdade de 
manifestação de pensamento. Afora qualquer idealismo relativo a uma liberdade irrestrita ou a uma sociedade civil autônoma, crença confinada a uma cultura letrada, é importante considerar os postulados de Habermas relativos à formação de espaços públicos para entender a construção de uma cultura de jornais, mais do que uma cultura de notícias.

Ainda que a narrativa histórica da esfera pública de Habermas ignore, em um primeiro momento, as justaposições entre a cultura aristocrática e o liberalismo, entre os vários circuitos de subliteratura, ou ainda as interdições existentes nos cafés e tavernas, sua idealização é válida para destacar com maior precisão a importância crescente do jornalismo na sociedade moderna, o que é chamado pelo autor, num primeiro momento, de "jornalismo de convicção" (HABERMAS apud SILVA, 2001).

A existência dos cafés e tavernas nos quais se entrecruzava uma diversidade cada vez maior de informações facilitou o desenvolvimento de práticas de escrita regular. Práticas que, por sua vez, alimentaram o trânsito de indivíduos ansiosos por obter notícias - fundamentais, frise-se, para sua orientação política e comercial, antecipando a formulação de Hegel sobre o jornal como a "bússola do homem moderno". Ao mesmo tempo em que a conversa alimentava pautas jornalísticas, o jornal atuava como um intermediário, deixando escritas informações de interesse civil.

A precocidade da delimitação da sociedade civil e do Estado na Inglaterra gerou uma situação bem menos tensa do que aquela percebida na França, de forma que o jornalismo construído nos dois países foi bastante diferente. Os lordes, acostumados com a presença desconcertante dos jornais, trataram de aumentar impostos, impor obstáculos e patrocinar jornais rivais para divulgar as suas ações e 
fazer sua defesa pública. Assim construiu-se no jornalismo britânico, com maior precocidade, uma pragmática discursiva voltada para o afastamento do sujeito do texto, o que seria capaz, em teoria, de fornecer maior precisão informativa. Pode-se dizer, por fim, que a solidez da esfera pública em Londres está ligada à solidez de suas práticas jornalísticas, patentes numa profissionalização crescente ao longo do século XVIII. 


\section{Referências}

BOISVERT, Georges. Commentaire sur l'ouvre Memorial a d. João VI, de Bernardo da Rocha Loureiro. Lisboa: Fundação Calouste Gulbekian/Centro Cultural Português, 1973.

CANNADINE, David. Contexto, Execução e Significado do Ritual: a Monarquia Britânica e a 'Invenção da Tradição, c. 1820 a 1977. In: HOBSBAWM, Eric. A invenção das tradições. Rio de Janeiro: Paz e Terra, 1997.

COOPER-RICHET, Diana. As grandes revistas literárias e políticas na formação das elites britânicas durante a primeira metade do século XIX. In: DUTRA, Eliana de Freitas; MOLLIER, Jean-Yves (Orgs.). Política, nação e edição. O lugar dos impressos na construção da vida política. São Paulo: Annablume, 2006.

COWAN, Brian. The social life of coffee. The emergence of the British coffeehouse. Yale: Yale University, 2005.

CRARY, Jonathan. Techniques of the Observer. On vision and modernity in the Nineteenth Century. Massachusetts: MIT, 1992.

CROUCH, Edmund. News from the Coffee-House; In which it is shewn their several sorts of Passions, Containing Newes from all our Neighbours Nations. A Poem. London, 1667. Disponível em: <http://www2.ivcc.edu/coburn/ENG\%201001/defining_a_coffeehouse.htm>. Acesso em: Abril de 2015.

CRUICKSHANK, Isaac. The Silent Meeting. London: Laurie \& Whittle, 1794.

DARNTON, Robert. Os dentes falsos de George Washington: um guia não convencional para o século XVIII. São Paulo: Companhia das Letras, 2005.

DICKINSON, William. The Coffeehouse patriots. 1781, Disponível em <http://www.loc.gov/pictures/item/2004673448/>. Acesso em: Abril de 2015.

ELIAS, Norbert. A sociedade de Corte: investigação sobre a sociologia da realeza e da aristocracia de corte. Rio de Janeiro: Jorge Zahar, 2001.

GOODMAN, Dena. Difference: An Enlightenment Concept. In: BAKER, Keith Michael. What's left of Enlightenment. A Postmodern Question. Stanford: Stanford University Press, 2001.

HABERMAS, Jurgen. Mudança estrutural da esfera pública: investigações quanto a uma categoria de sociedade burguesa. Rio de Janeiro: Tempo Brasileiro, 2003.

HESSE, Carla. Print culture in the Enlightenment. In: FITZPATRICK, Martin. The Enlightenment World. New York: Routledge, 2004.

KELLY, Jason, Revelries and Rumor: Libertinism and Masculine Association in Enlightenment London. Journal of British Studies, v. 45, n. 4, pp. 759-795, 2006.

KLEIN, Lawrence. Enlightenment as conversation". In: BAKER, Keith Michael. What's left of Enlightenment. A postmodern Question. Stanford: Stanford University, 2001.

McLUHAN, M. A galáxia de Gutemberg. São Paulo: Edusp, 1972.

MELTON, James van Horn. The Rise of the Public in the Enlightenment Europe. Cambridge: Cambridge University Press, 2001.

MUNARO, Luís. O Jornalismo português em Londres (1808-1822). Retrato de um tempo e de uma profissão. Rio de Janeiro: Publit, 2014.

PORTER, Roy. Enlightenment London and Urbanity. In: HEMMING, T.D.; MEAKIN, D. The Secular City: Studies in the Enlightenment. Exeter: Univeristy of Exeter, 1994. 
The Enlightenment. In: BORSAY, Peter. The Eighteenth-Century Town: A Reader in English Urban History, 1688-1820. London: Longman, 1990.

ROGERS, Pat. Grub Street. Studies in a Subculture. London, New Fetter Lane, 1972.

ROSANVALLON, Pierre. O liberalismo econômico. História da ideia de mercado. Bauru: EDUSC, 2002.

SILVA, Filipe Carreira. Habermas e a esfera pública: reconstruindo a história de uma ideia. Plataforma democrática, 2001. Disponível em: <http://www.plataformademocratica.org/ Publicacoes/Publicacao_9362_em_06_06_2011_12_34_08.pdf>. Acesso em: Abril 2015.

WASSON, Ellis Archer. The Whigs and the press, 1800-50. Parliamentary History, v. 25, Part 1, pp. 68-87, 2006.

WRIGHT, Johnson Kent. 'A Bright Clear Mirror': Cassirer's The Philosophy of the Enlightenment". In: BAKER, Keith Michael. What's left of Enlightenment. A postmodern Question. Stanford: Stanford University, 2001.

\section{Nota de reconhecimento}

Um esboço deste trabalho foi apresentado no GT Historiografia do III Encontro Regional Norte de História da Mídia, em 2014.

COMPOLITICA ASSOCIACCÃO BRASILEIRA DE PESQUISADORES EM COMUNICACÃO E POLIITICA

Diretoria da Associaçâo/Director Board

Presidente | President

Fernando Lattman-Weltman (UERJ)

Vice-Presidente | Vice-President

Arthur Ituassu (PUC-Rio)

Secretária Executiva | Executive Secretary

Kelly Prudêncio (UFPR)

Corpo Editorial / Editorial Board

Editoras-Chefes: | Chief-Editors

Alessandra Aldé (UERJ) \& Maria Helena Weber (UFRGS)

Editores Executivos | Executive Editors

Fernanda Sanglard (UERJ), Rafael Cardoso Sampaio

(UFMG) \& Viktor Chagas (UFF)
A Revista Compolítica é uma revista eletrônica da Associação Brasileira de Pesquisadores em Comunicação e Política

[Revista Compolitica is an electronic journal published by the Brazilian Association of Political Communication Scholars]

Ao citar este artigo, utilize a seguinte referência bibliográfica

[To cite this article, please use the following reference]

MUNARO, Luís Francisco. A articulação de jornalismo e espaços públicos na Ilustração Inglesa. In: Revista Compolítica 5 (1), 2015. 
